\title{
Medida e desmedida \\ na Rítmica de José \\ Eduardo Gramani
}

\section{Alexandre Piccini Ribeiro Marcelo Pereira Coelho}

\begin{abstract}
Resumo: Este texto nasce do interesse mútuo de duas linhas de pesquisa em música que tem o ritmo como ponto de encontro. No foco de nossas conversas encontram-se as séries e polimetrias do prof. José Eduardo Gramani, que suscitam desdobramentos na área composicional e filosófica. Revisitando os resultados relatados no laboratório de composição e improvisação rítmica do departamento de música da USP, propomos aqui uma reflexão sobre a possibilidade de uma ideia não medida de ritmo.
\end{abstract}

Palavras-chave: Rítmica, Gramani, Filosofia Deleuze

WHAT IS MEASURED AND UNMEASURED IN THE RHYTHMIC APPROACH OF JOSE EDUARDO GRAMANI

Abstract: This paper arises from the mutual interest of two lines of research in music that has the rhythm as the meeting point. The main focus is the compositional and philosophical processes based on the polimetries called "Series", developed by the professor José Eduardo Gramani. Revisiting the results of the laboratory of composition and improvisation based on the Gramani's rhythmic concept, which was reported to USP music department, we propose a reflection on the possibility of a rhythmic idea not to be measured.

Keywords: Rhythm, Gramani, Deleuze, Philosophy 


\section{Gramani e algumas notas sobre sua pesquisa em educação rítmica}

José Eduardo Ciocchi Gramani (1944-1998) atuou como concertino e regente à frente de diversas orquestras brasileiras; dedicou-se à música de câmara, à composição e à pesquisa musical, além de ter exercido singular e marcante atividade como professor de música. No entanto, sua proposta de educação rítmica é, certamente, uma de suas maiores contribuições.

O processo de amadurecimento de suas ideias, que culminou na publicação dos volumes Rítmica e Rítmica Viva, floresceu nos anos de experiência como aluno e professor da FASCS, Fundação das Artes de São Caetano do Sul (São Paulo).

Entre 1969 e 1973. Gramani foi aluno da professora Maria Amália Martins que desenvolvia um trabalho fundamentado na metodologia de Emile Jacques-Dalcroze, cuja importância pedagógica viria a vascularizar seu pensamento na contra direção do racionalismo estrutural, em favor de uma ideia ainda romântica que coloca a sensação e a expressão como preponderantes no universo artístico.

A sensibilidade, como prerrogativa maior da arte, talvez tenha atravessado o ideário romântico e desembocado em importantes reflexões tanto em Dalcroze como em Gramani, para os quais o sentir deve ser buscado de maneira dominante em suas propostas, enriquecendo a compreensão e o exercício do estatuto musical.

Para Dalcroze (apud Rodrigues, 2001, p. 6), a finalidade da Rítmica consiste em:

colocar seus adeptos, ao terminar os estudos, na situação de poderem dizer: eu sinto em lugar de eu sei; e, especialmente, desperta-lhes o desejo imperioso de expressarem-se, depois de terem desenvolvido suas faculdades emotivas e sua imaginação criadora.

A proposta de Dalcroze, para quem a educação rítmica seria uma forma de triunfar sobre as inibições e resistências levando o estudante à condição de 
realizar descobertas, convida a uma reflexão do significado do aprimoramento da sensibilidade rítmica como forma de instigar a curiosidade e a prática investigativa.

Este conceito, referente à percepção do ritmo enquanto estímulo, tornarse-ia fundamental na proposta rítmica de Gramani.

Em um dos textos que permeiam o caderno de estudos Rítmica Viva, Gramani (1996, p.13) assevera que os exercícios teriam "por finalidade o aprimoramento da sensibilidade rítmica", em que o corpo atuaria como interface de assimilação e conscientização da ideia musical inerente a uma estrutura rítmica. Mas Gramani vai além em seu trabalho, ampliando sobremaneira o sentido da educação voltada ao senso métrico, possível influência do trabalho Rítmica Métrica de Rolf Gelewski.

Assim como Dalcroze, Gelewski também explora a vivência do ritmo através de percussões corporais e, até mesmo, grafismos, em exercícios individuais e coletivos voltados à composição, leitura e improvisação. Vejamos como Rodrigues (2001) o coloca:

O aspecto marcante e diferenciador de seu método de educação rítmica consiste no fato de ele estar baseado, quase exclusivamente, em modelos ou fórmulas métricas ${ }^{1}$. Esse aspecto é realmente relevante, pois enfatiza a noção de compasso, inclusive o compasso alternado e misto (Rodrigues, 2001, p. 18).

Em seus estudos, Gramani também baseia sua notação no valor da brevidade, ou seja, determinação da unidade, proporcionalmente, pelo menor valor envolvido no jogo polimétrico, tal que o menor valor seja a base do cálculo das proporções. Trata-se de um procedimento fundamentado no pensamento aditivo em que todos os valores são possíveis unidades e devem ser focados, até certo ponto, isoladamente. Na rítmica aditiva, os valores são pensados, em função das suas próprias unidades internas, como pulsações e não como subdivisões.

\footnotetext{
${ }^{1}$ Fórmulas Métricas, utilizadas por Gelewski, são combinações de valores curtos e longos na proporção de 1 para 2. Assim, o binário: prop: [1.1], o ternário: prop: [1.1.1] [1.2] [2.1], o quaternário: prop: $[1.1 .1 .1][2.2][1.1 .2][2.1 .1][1.2 .1]$ etc.
} 
Segundo Gelewski, essa ideia propicia ao estudante, além da educação das "qualidades rítmicas”, "a 'intensificação da consciência' através da estreita concatenação do treinamento de faculdade cerebrais (em especial, a concentração) com atividades rítmico-físicas" (Gelewski, 1967, p. 5).

A música de Igor Stravinsky também parece ter sido uma importante fonte de informação e inspiração para o desenvolvimento das propostas de Gramani. Sobre a relação entre a música de Stravinsky e os seus estudos rítmicos polimétricos, Gramani (1986 apud Rodrigues, 2001, p. 44) comenta:

Em 1981 [...] estava estudando a parte de violino de 'A História do soldado', de Stravinsky, e, tendo dificuldades em alguns trechos, comecei a estudar os contrapontos rítmicos fantásticos que ele escreveu. [...] montei alguns trechos a duas vozes rítmicas e estudei, resolvendo alguns problemas. Então levei os exercícios para meus alunos na UNICAMP, eles estudaram e o resultado foi muito bom. Isso me animou a pensar em porque não estudar o ritmo com aquelas características.

Notamos que, bem como na rítmica de Stravinsky, uma prática constantemente encontrada em seus estudos é o uso sistemático de ostinatos. Assim como Stravinsky, Gramani também utiliza o ostinato com a finalidade de contraste e oposição de movimentos.

O ostinato, como modo de repetição, exerce tal como vimos na exposição do pensamento aditivo, uma função de unidade polimétrica na sobreposição das linhas rítmicas.

Em Conversas com Igor Stravinsky, quando interrogado sobre a função do ostinato, o compositor responde "é a estática [...], o antidesenvolvimento [...]; uma contradição ao desenvolvimento" (Stravinsky, 1999).

A necessidade de instruir o músico a respeito da correta execução e percepção do evento rítmico é uma inquietação comum a ambos os músicos, e a preocupação quanto a independência expressiva dos eventos rítmicos, os aproximam veementemente.

Durante cinquenta anos [...] me empenhei em ensinar [aos músicos] a acentuar as notas sincopadas [...] quando irão os músicos aprender a 
abandonar a nota ligada, a suspendê-la e não apressar as colcheias em seguida? (Stravinsky, 1999).

Gramani, em um dos seus textos, faz uma menção relativa a essas mesmas deficiências quando diz que "no ensino tradicional, o ritmo é [...] normalmente subordinado aos tempos [do compasso], gerando muitas vezes descaracterizações no âmbito musical" (Gramani, 1992, p. 11).

De todo modo, as observações e simpatias entre a Rítmica de Gramani e certos aspectos das ideias de Dalcroze, Stravinsky e Gelewski ganham uma orientação consistente numa pedagogia da sensibilidade, se é que podemos falar assim quanto à obra de Gramani.

No apoio de uma decidida pragmática, Gramani faria tender sua métrica, segundo nossa hipótese, a um limite de desmesura que desafiaria a sensibilidade musical dos estudantes.

O contraponto tornar-se-ia o princípio de desvinculações verticais, à medida em que os valores adicionados tornam-se elementos de variação e deslocamento nos jogos polimétricos. O tempo, até então tomado como base comum na proporção das estruturas, torna-se objeto de reversão pedagógica.

É preciso antecipar, aqui, o sentido precursor e ilustrativo de Kant tanto na reversão entre o condicionamento dado entre tempo e movimento, quanto na pontuação de certo desacordo das faculdades numa situação limite, evidenciado em sua análise do sublime.

$\mathrm{O}$ ritmo, sob tal perspectiva, alça-se, paradoxalmente, por meio de uma aparentemente simples adição métrica, a um jogo mais severo de disjunções e deslocamentos no qual a própria métrica encontra seu termo de desmesura, desafiando a sensibilidade a proceder por seus próprios meios.

Em parte por esses motivos, e talvez sem muita consciência dos caminhos pelos quais passou, é possível que Gramani tenha tocado em pontos centrais da filosofia contemporânea, questionando a hegemonia da linearidade cronométrica do tempo em direção aos temas extemporâneos da duração, nas quais concorrem, entre outras, as filosofias de Kant, Nietzsche, Bergson e mais recentemente Gilles Deleuze. 
De todo modo, o que nos interessará daqui em diante são as possíveis aproximações entre a Rítmica de Gramani e algumas reflexões sobre os conceitos de Tempo e ritmo que mesmo em seus trajetos mais rigorosamente bem fundados, encontram dificuldades importantes, tais quais as que fizeram Deleuze avivar em Kant um profundo terror hamletiano: The Time is out of Joint ${ }^{2}$.

\section{O elemento musical não deve ser identificado ao elemento aritmético}

Nas páginas introdutórias do volume Rítmica, José Eduardo Gramani (Gramani, 2010, p. 11-12) esclarece, de maneira econômica, algumas de suas posições e ideias acerca da sua proposta quanto ao estudo do ritmo.

Ao afirmar que os seus estudos são "exercícios para que o músico sinta mais e conte menos" (Gramani, 2010, p. 11) Gramani prepara o leitor para o confronto existente entre associação versus dissociação rítmica, uma das contribuições mais originais da sua metodologia.

A independência da métrica e da subdivisão a partir de vários planos rítmicos, que se superpõem e se relacionam em forma de contraponto, contribuem para evitar o condicionamento centrado na decodificação, associação e sincronicidade das combinações rítmicas como forma de resolução.

Gramani entende ser preciso desarticular a frase rítmica de sua subordinação ao tempo, uma vez que ela "acontece sobre ele” (Gramani, 2010, p. 11). A seu modo, Gramani reflete a chamada "revolução copernicana" de Kant, que liberou o tempo de sua subordinação ao movimento: "é o movimento que se subordina ao tempo [...] Não é a sucessão que define o tempo, mas o tempo que define como sucessivas as partes do movimento tal como nele estão determinadas" (Deleuze, 1997, p. 37).

O pulso como movimento já não determina mais o Tempo como ordem cronométrica mas como forma pura, vazia, ordinal.

\footnotetext{
${ }^{2}$ Shakespeare, Hamlet, I, 5 ("The time is out of joint")
} 
De maneira ilustrativa, Gramani faz sua revolução tirando tempo "dos gonzos" ou eixos verticais do pulso, por uma simplória adição de valores.

O efeito de anterior subordinação, como demonstrada no Exemplo (1), desnatura a ideia musical ao alterar o sentido dos apoios, acentuações e dinâmicas.

Exemplo 1 - excerto do livro Rítmica de Gramani (2010, p. 18)

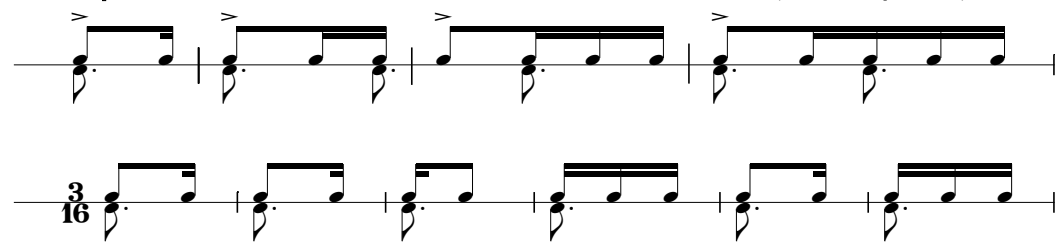

Enquanto a proposta de Gramani enfatiza a linearidade da primeira ideia, a notação tradicional, ao rebatê-la sobre um tempo de base do 3/16 a desnatura, neutralizando o sentido musical dos apoios.

Embora as durações se equivalham, é possível perceber que o modo de agrupamento das notas sugere apoios rítmicos bastante diferentes.

O aspecto contrapontístico das frases deve ser radicalizado na sua realização, pois mesmo o contraponto pode compactuar com uma leitura "harmônica" que o submeteria ao alinhamento vertical.

No contraponto, por outro lado, algo nasce, de outra natureza, e que não pode ser identificado à soma das partes ${ }^{3}$.

A individualização de cada frase rítmica torna-se então o processo único capaz de instaurar a dissociação entre as vozes, trazendo à tona a realidade musical implícita em cada frase.

Preocupado com a expressividade rítmica do discurso, Gramani recomenda, então, uma prática - meios de “criação de novas associações", que a partir do exercício da sensibilidade, desafiam os clichês sensório-motores que regulam a leitura e os movimentos do corpo.

\footnotetext{
${ }^{3}$ Note-se que, por si só, a mera serialização dos valores, ao provocar a ampliação gradativa dos agrupamentos rítmicos, já induz a série a um contraponto silencioso. Entre ela e o silêncio já se induz um pulso abstrato que o hábito aguarda e que deve ser vencido.
} 
É preciso ativar a criação de novas associações, fruto da dissociação das já existentes, gerando maior consciência na utilização de movimentos, gestos e atitudes (Gramani, 2010, p. 12).

Todavia, esta ampliação de relações corporais e intelectuais que a prática das estruturas proporcionam, não tem como finalidade a extensão do vocabulário rítmico, consistindo, sim, um "meio" de desenvolvimento musical pela sensibilidade 4 .

Estes exercícios não são um fim e sim um MEIO através do qual muito pode se desenvolver, principalmente os aspectos de disciplina interior e flexibilidade de adaptação da atenção a novos tipos de associações ou relações. Quando o exercício já estiver sendo bem realizado já deixou de ter sua função, pois os problemas que dificultavam sua realização já foram solucionados através de processos interiores de associação e dissociação. 0 desenvolvimento destes processos é que é o FIM. O objetivo dos exercícios, pois, é que funcionem como veículo para que tais processos possam chegar à nossa sensibilidade (Gramani, 2010, p. 12, grifo do autor).

Gramani (1992, p. 12) propõe “vencer desafios aritméticos através da sensibilidade musical", sugerindo que o ritmo deve ser vivido e vivificado num corpo e que a rítmica não deve ser reduzida ao estado abstrato, matemático ou racional dos arranjos rítmicos, sem perder a complexidade e a força de heterogeneidade em mobilidade num corpo.

Seu interesse prático pelo exercício o impede de divagar pela inteligência, pela razão ou pelas categorias do entendimento, pois compreendia que só pela prática $^{5}$, pela instituição problemática das séries, ostinatos e polimetrias poderia chegar à sensibilidade como faculdade limite.

${ }^{4}$ É preciso destacar aqui que a sensibilidade, segundo o modo ligeiro como Gramani a estima, não é a faculdade submetida ao harmonioso acordo kantiano (senso comum) e que teria, como objeto, o sensível empírico; aqui a sensibilidade aguarda o objeto transcendental suprassensível que Kant intui em sua terceira crítica na sua leitura do sublime (Crítica da Faculdade de Julgar, § 26-29), e que a submete a um limite próprio e que a impele a um esforço disjuntivo, a um descordo. A sensibilidade, é então, o operador de um empirismo invulgar, que tem seu objeto naquilo que se trai no fenômeno, a saber um signo, multiplicidade virtual. (Cf. Deleuze, 2006, p. 203-204)

${ }^{5}$ A prática, no entanto, ou a pragmática, se assim a quisermos, não deve ser reduzida a um conjunto de ações num meio. Se é certo que toda ação necessita de um meio, no qual se realiza, toda pragmática, que não se confunde com um convencionalismo, envolve uma política que se manifesta nos meios. Sugerimos aqui que a prática das polimetrias envolve 
O apelo à sensibilidade como faculdade privilegiada na prática dos exercícios expõe a clareza com que Gramani entendia o lugar secundário da inteligência e do conhecimento no processo de realização. Se a inteligência pode encarar com tranquilidade a abstração dos modos métricos de arranjos das frases e polimetrias, nos parece claro sua relativa impotência na realização plena dos exercícios.

Lançar a aritmética das estruturas ao estado de consistência musical é, portanto, uma tarefa que a sensibilidade realizaria sob a condição de se ter um corpo que as experimentam acrescentando-Ihes um horizonte fluido e estrangeiro, fruto da sensibilização das relações, que se voltadas à pauta de Dalcroze seriam vistas sob um estado de alegria (joie), transbordando toda a medida:

La joie d'évoluer rythmiquement, de donner tout son corps et toute son âme à la musique qui nous guide et nous inspire est une des plus grandes qui puissent exister (Dalcroze, 2009, p.15)

\section{O corpo introduz no tempo medido a desmesura do tempo}

Sabemos que o ritmo escrito encontra sempre uma medida. Essa medida pode ser relativa. Medimos, por exemplo, as durações a partir da proporcionalidade inerente às células ou grupos rítmicos ou a um tempo de base, que se subdivide abstratamente numa estrutura qualquer.

Esta relação proporcional das medidas se mantém na execução dos ritmos e ganha uma variação concreta no ajuste dos andamentos. Vamos mais rápido ou mais devagar; variamos o andamento, mas mantemos sempre um senso de proporção e medida absoluta.

Podemos dizer que, mesmo expressando esses valores em medidas irracionais, em dízimas que acompanham certas divisões do tempo ou em

uma política pré-intelectual dos afectos que circulam no tempo e insistem nas figuras dando-lhes volumes, que são volumes de relações, sensações, de conexões diferenciais entre os diversos pontos de vista tomados por uma subjetividade musical que ali se esboça no limite problemático da ação. Veja quanto a isso a insistência de Gramani quanto ao abandono dos exercícios quando o estudante os automatiza. 
variações radicais de andamento, sempre haverá um número que acompanha o fenômeno.

Há aqui um pouco de espaço no tempo ${ }^{6}$ Na verdade há muito espaço nessa concepção do tempo; o tempo torna-se, na medida do transcurso, uma grandeza espacial ou especializada.

Tal espaço pode ser graduado em estruturas, proporcionalizado, relativizado, estriado, mas também pode se alisar ou ser visto sob um ponto de vista topológico.

O Tempo ganha contornos; contornos energéticos que lhe dão certa curvatura, certa complexidade; passa a ser percebido sob certas distinções regionais (ou seccionais), que se separam nas diferenças destes contornos, na fluidez de uma topologia energética que não obstante recai em formas, frases, estruturas.

Passamos incessantemente, num certo quadro de escuta, de uma física, de uma estética a uma analítica, e o Tempo ora se esvazia no aspecto sincrônico da estrutura ora ganha seus volumes numa realização concreta.

No entanto, ladeando essas concepções do tempo, há ainda uma outra maneira de compreendê-lo, bem como a duração e o ritmo. Um modo nãomedido, intempestivo de ocupar o tempo; um modo de temporalidade que insiste na energética do tempo físico, e que sustenta semioticamente o valor das estruturas.

Tal modo de insistir no tempo requer um novo uso do léxico, que perverte a nomenclatura cotidiana em favor de uma "vidência" que contempla a complexidade do Tempo - particularmente na sua relação com o corpo.

Um corpo experimenta o espaço. E qual é o modo de um corpo se relacionar com um espaço? O corpo é afetado pelas componentes de um espaço diferentemente de uma relação intelectual da razão ou do entendimento. 0

6 A concepção do espaço pertence à inteligência, mas a sensação do espaço, nosso envolvimento nele, é material da sensibilidade, ainda que tais experiências possam ser recobertas pela inteligência. A reversão, no entanto, é flagrante quando a música ocupa o tempo musical como um espaço, com suas métricas, seus andamentos e eventos. O curioso é que é o Tempo (ou Aion estoico) como grandeza acontecimental e intensiva que se expressa nas fendas do tempo espacializado de Cronos. 
espaço da performance é, sobretudo, um espaço a ser conquistado em sua relação com os afetos aos quais o músico é exposto.

Quando Gramani introduz o corpo em suas prerrogativas, está sendo muito sábio e coerente com relação às suas propostas: [...] Bata com a mão esquerda, alterne os pés, sinta a pontuada, agora reja com a direita, cante a série tal [...]. Recursos que falseiam a razão e introduzem, a partir do corpo, um confronto entre a sensibilidade e o hábito; experiência que expõem o limite de nossos clichês cerebrais, e que exige, mais que sua expansão, um remanejamento, onde só haviam recognições de ordem aritmética.

Mas Gramani introduz, antes do instrumento, o corpo, ou o corpo do instrumento, sob a condição de que não se reintroduza, a partir dele, seu conjunto de hábitos e soluções.

E por que é preciso um corpo? Porque o corpo é a sede de um verdadeiro manancial de problemas que só no corpo podem se dramatizar.

É preciso de um corpo e daquilo que ele pode, ou do que ainda não pode, em razão de seu fechamento em seus hábitos. E abrir o corpo aos afetos de um espaço é torna-lo sensível ao elemento pré-intelectual que se é ritmo ainda não pode ser notado.

De todo modo, o corpo é portador de uma outra imagem temporal, e que nos interessa. Dimensão não-cronológica, inatual, intempestiva, aiônica. Os termos variam conforme os autores e épocas, mas se mesclam de maneira muito íntima.

Com efeito, para ser estrito, a própria materialidade do corpo pode ser compreendida como uma distensão real da Duração e do Tempo, se aqui nos ativermos à imagem metafísica que Bergson nos dá.

E se a razão nos oferece algumas ideias verossímeis do Tempo, nos parece que, desde sempre, é o corpo que irá introduzir no tempo musical um elemento de disparidade e desmesura ${ }^{7}$, desafiando as ideias da razão e as categorias do

\footnotetext{
${ }^{7}$ Nossa ideia de desmesura apresenta ao menos duas componentes que precisam ser, senão explicadas, indicadas. A primeiro requer a distinção respectiva entre a extensio e o spatium, qualidade e intensidade, espaço e tempo. O universo da desmesura é sempre uma duração, um espaço topológico ou intensivo; profundidade metafísica que não admite aspectos espaciais, e portanto, medíveis. Somando-se a isso gostaríamos de acrescentar a ideia da hybris grega, como medida ou limite que não temos o direito de transpor. Na poética, Aristóteles vê a hybris como limite a partir da qual toda tragédia advém. Limite ou extremo de negação, a hybris torna-se uma virtude nos termos intensivos de uma potência que se
} 
entendimento, reservando ao Tempo um desenvolvimento conceitual alheio às nossas afinidades com a compreensão do espaço.

A música parece estar cheia disso. Ela se faz com a desmesura de um entretempo que se insinua no tempo, um tempo rachado, fora dos gonzos, e é a sensibilidade que introduz, a partir do corpo - na condição de se haver um corpo - o elemento paradoxal ou virtual que ali se aloja como bloco de sensações.

Só o corpo, como sede do movimento e arcabouço da complexidade da experiência pode dotar a energética, a estrutura e o tempo medido de um elemento de desmesura, a saber, uma duração ou o próprio Tempo; como dizia Proust na Recherche "um pouco de tempo em estado puro", ou conforme a aproximação bergsoniana, o tempo como multiplicidade substantiva ${ }^{8}$.

\section{O ritmo é incomensurável e crítico}

O tambor não é 1-2, a valsa não é $1,2,3$, a música não é binária ou ternária, mas antes 47 tempos primeiros, como nos turcos. É que uma medida, regular ou não, supõe uma forma codificada cuja unidade medidora pode variar, mas num meio não comunicante, enquanto que o ritmo é o Desigual ou o Incomensurável, sempre em transcodificação. A medida é dogmática, mas o ritmo é crítico, ele liga os instantes críticos, ou se liga na passagem de um meio para outro. Ele não opera num espaço-tempo homogêneo, mas com blocos heterogêneos. Ele muda de direção. Bachelard tem razão em dizer que "a ligação dos instantes verdadeiramente ativos (ritmo) é sempre efetuada num plano que difere do plano onde se executa a ação". O ritmo nunca tem o mesmo plano que o ritmado. É que a ação se faz num meio, enquanto que o ritmo se coloca entre dois meios, ou entre dois entremeios, como entre duas águas, entre duas horas, entre lobo e cão, twilight ou zwielicht [...] Por aí, saímos facilmente de uma aporia que corria o risco de trazer a medida de volta para o ritmo, apesar de todas as declarações de intenção [...] É a diferença que é rítmica, e não a repetição que, no entanto, a produz; mas, de pronto, essa repetição produtiva não tinha nada a ver com uma medida reprodutora (Deleuze e Guattari, 2005, p. 119-120).

excede num limite. Ir além deste limite é encontrar o elemento de desmesura que dá ao Ser e ao Pensamento a potência seletiva de retornar, de repetir-se sob a condição de se querer à enésima potência (Cf. Deleuze, 2006, p. 73-74).

${ }^{8}$ Sugerimos os textos de Pelbart (1998) quanto a imagens muito elucidativas da ideia de tempo. 
Gramani cria ritmos em sua obra: células, séries, ostinatos, polimetrias, contrapontos etc., todos passíveis de uma relação justa com a razão e com o entendimento. Coelho (2008) e Rodrigues (2001) expuseram com clareza a gênese métrica das estruturas de Gramani, ainda que pouco enfatizadas pelo próprio autor.

No entanto, sua autêntica invenção no campo do ritmo está em ultrapassar a métrica das estruturas em direção à atividade e à sensibilização rítmica, aspectos que parecem interessar Coelho em seus laboratórios de composição e improvisação.

Mais do que a adequação das estruturas a uma situação musical concreta, os exercícios visam (e são meios de) experimentações, nas quais a sensibilidade sobrevém à compreensão das estruturas.

Conforme sugerimos alhures, para Gramani, é preciso recorrer à “sensibilidade musical" para que esta, "agregada ao raciocínio aritmético, possibilite uma realização musical dos exercícios" (1996, p. 104).

A prática dos ritmos que Gramani inventa só se torna, de fato, invenção, na medida em que o ritmo, mais que assimilado a um jogo de proporção e permutações de valores (encontrados de modo diverso no repertório tradicional), se torna crítico na relação entre as estruturas (relação que Gramani ressalta como problemática e que julga pertinente abandonar após a automatização dos exercícios).

Postulamos, com Deleuze, que na relação diferencial o ritmo se torna um “entre”. Ele já não é idêntico às figuras de uma linha ou outra, mas o efeito da relação que convida a sensibilidade a compreendê-lo por seus próprios meios. Revisitando o projeto de Dalcroze, o dizer incorruptível do "eu sinto" e não mais do "eu sei".

O ritmo então já não é medido em proporção em unidades abstratas ou concretas; torna-se meio de modulação, o Desigual, e apela à sensibilidade levada ao limite transcendental de seu exercício.

Silvio Ferraz (1998, p. 190) ressalta as estratégias e visões de Messiaen quanto às irregularidades de sons da natureza com seus "politempos", 
atravessando a unidade do pulso sob um carretel heterogêneo de durações que se acotovelam.

As peças de Messiaen, posteriores a Le merle noir (1951) e Réveil des oiseaux (1953), permitem essa experiência de levar as faculdades cognitivas ao limite em que "fervilham as diferenças". A partir desse período, a obra de Messiaen vê surgir cada vez mais momentos de sobreposição: sobreposição de cantos de pássaros (de um mesmo continente e de vários continentes), sobreposição de ritmos, sobreposição de "cores". Com isto o compositor buscava um caminho para acabar com o tempo cronológico e direcional e estabelecer a duração da eternidade e do vivido, tecendo em sua música uma superfície que mergulha o ouvinte num devaneio de irregularidades métricas, em que o tempo é vago e ondulante (Ferraz, 1998, p. 190).

O limite, que Ferraz menciona, é o limite transcendental deleuzeano "em que fervilham as diferenças". Limite que obriga a sensibilidade a sentir o que só pode ser sentido, e não mais imaginado ou entendido (num eventual acordo objetivo). A falência da imaginação e do entendimento ante às percepções aritméticas propostas por Messiaen ou Gramani evidenciam, portanto, que o ritmo, em ambas as concepções, só pode ser, propriamente, o objeto transcendental da sensibilidade, não obstante destituído de superfície sensível.

Mas e o ritmo que se lê, se solfeja e que conquistamos paulatinamente nos manuais tradicionais, obedecem a qual estatuto? Dizemos que o ritmo que se lê é um código, permanência abstrata de certos aspectos do ritmo. Aqui nos vem à mente os clichês cunhados na história, todo o repertório de figuras e frases que encorpam nosso vocabulário musical, e que evidentemente, não os desmerecem.

De fato, parece ser preciso estar à altura dos eventos que os sustentam para interpretá-los em contextos musicais. Se a aritmética é um aspecto que nos ajuda na realização musical ela deve, contudo, se fazer acompanhada de ampla experimentação que certamente faria reingressar, no ritmo escrito, uma carga extranumerária ou acontecimental produzida na experiência e que insiste nas leituras de maneira tácita, principalmente sob a forma cultural de um conjunto de escutas.

A este ponto podemos dizer, já, que nossa ideia de ritmo se enfraquece se polarizado na compreensão métrica das estruturas. O que criticamos nessa 
posição, com a sobrevinda do pensamento de Bergson, é que a métrica estrutural espacializa e "esvazia" o Tempo, tornando-o uma grandeza análoga ao espaço. O ritmo é crítico, e toma melhor figura nos ambientes inventivos de improvisação.

O ritmo é crítico e envolve, portanto, certa vulnerabilidade quanto a seus modos de sustentação, o que certamente sustenta a pluralidade de problemas da performance. O ritmo, por definição, é vivo e vivificante; ele atua num meio, o faz vibrar, estando sempre "entre". O ritmo crítico é o léxico do Tempo.

\section{Saindo da música pela filosofia}

Nada indica, pelo menos em textos, que o pensamento de Gramani tenha tal ou qual compromisso filosófico. Vimos que em sua formação e em sua prática educativa, Gramani cultivou contatos e mostrou simpatias por compositores e pensadores, mas em momento algum se propôs à defesa de suas ideias a partir de referências alheias à sua viva experiência.

Sem dúvida observamos sintonias com certas correntes de ideias, mas, de qualquer modo, somos levados a entender que a arte não precisa e nada deve à filosofia como atividade de pensamento.

Com Deleuze e Guattari (1992, p. 213) estamos atentos a crer que a experiência da música é uma atividade autônoma de pensamento e que, diferentemente da filosofia, cujo modo de pensar se dá por conceitos, o pensamento musical se sustenta por sensações, afetos e perceptos que duram numa matéria sonora.

O que fazemos aqui também é uma experiência, muito embora focada na transversalidade dos campos musical e filosófico. Sujeitos a um grande entusiasmo pelo empirismo, apreendemos o sentido prático de um texto; de fato, a própria teoria é uma prática, uma experiência do pensamento. Tal como na música, os textos nos fazem confrontar posicionamentos diversos e experimentarmos, a partir disso, ritmos que se trocam, batimentos, sintonias e ressonâncias.

Um meio reage sobre outro, e entre eles, subsiste o ritmo como atividade modulante exterior aos meios em que a ação se desenrola. De repente somos 
levados por uma breve sonoridade a um turbilhão de conceitos, ou sentimos que um conceito ganha matizes extraordinários numa musicalidade qualquer.

Boulez provou com maestria essa intensa onda, esse hábito nas vagas interessantíssimas do conceito e dos perceptos. Uma ideia musical pode, de alguma maneira, envolver um modo filosófico ou conceitual de ver o mundo e o insinuar como espectro modulante numa matéria sonora.

Já não era o espectro (então fantasmagórico) que acometeria Hamlet a provocar o seu mortificante the time is out of joint? A forma transcendental do tempo balançaria de maneira decisiva as estruturas lineares do tempo, agravando sua ruptura contemporânea na diversidade processual do século XX.

Silvio Ferraz (1998, p. 183-210), analisa em seu Música e Repetição aspectos importantes da rítmica de Messiaen, mostrando que, tal como na reversão kantiana entre tempo e o movimento "O tempo é o que se desenrola, e não as coisas se desenrolam no tempo" (Ferraz, 1998, p. 210).

Tais análises corroboram o tema inicial que Ferraz subtrai de Deleuze e que reproduzimos a seguir:

fazer do som o artifício que torna o tempo sensível (...) organizar o material para captar as forças do tempo e torná-las sonoras: este é o projeto de Messiaen (BPT, p. 100) (Ferraz, 1998, p. 183).

De qualquer forma, se nos reportarmos à música de Messiaen, Cage, Boulez, Schaeffer, Stockhausen, Reich e tantos outros veremos que há, já aí, uma nova modalidade do pensamento insistindo nos modos tradicionais de se sentir e compreender música.

E se a música popular, tão cara a Gramani, se sente de modo mais modesto com relação ao pensamento conceitual, isso de maneira alguma diminui sua força como meio de expressão rítmica, já que uma diversidade enorme de territórios musicais e existenciais se sinalizam através dela.

Evidentemente já não nos controvertemos aqui de modo pueril com relação à ideia de ritmo, e se algo se expressa nos materiais dos quais a música dispõe, dizemos, não sem certa cautela, que esse algo são as próprias tensões ou 
graus da duração que se desenvolvem nos extensos, mas que se furtam à discriminação empírica da sensibilidade.

Neste sentido, já estamos na esfera dos signos e não mais acerca de objetos de uma percepção fenomenológica, conteúdos de futuras categorizações da escuta.

Mas se o ritmo é atividade crítica que se estabelece entre dois, todavia estar entre dois já é estar entre muitos. Dizemos um e outro como um vício de linguagem; na verdade há muito de um no outro e de outro no um. A história das ideias já nos precaveu o suficiente quanto a sabermos ou não ao certo onde o um começa e o outro acaba.

Kant já havia criticado o cogito cartesiano provocando uma segunda emancipação do tempo. Descartes opera a laicização ou a secularização do tempo quando faz do eu penso a determinação de uma substancia pensante que já não depende da mediação divina. No entanto, como mostra Kant, seria preciso ainda dizer "de que maneira ele é 'determinável”. A resposta é : "somente no tempo, sob a forma do tempo, que a existência indeterminada torna-se determinável. Assim o eu penso afeta o tempo e só determina a existência de um eu que muda no tempo e apresenta a cada instante um grau de consciência" (Deleuze, 1997, p. 38). Segundo este percurso Deleuze pretende chegar a evidência de um eu passivo (e não meramente receptivo, como em Kant) que racha o Eu cartesiano, dado que algo o divide por dentro, a saber, a potência de variação do tempo, como forma de interioridade:

A interioridade não pára de nos escavar a nós mesmos, de nos cindir a nós mesmos, de nos duplicar, ainda que nossa unidade permaneça. Uma duplicação que não vai até o fim, pois o tempo não tem fim, mas uma vertigem, uma oscilação que constitui o tempo, assim como um deslizamento, uma flutuação constitui o espaço ilimitado (Deleuze, 1997, p. 40).

O progresso dessas ideias irá dar a Deleuze a condição de dizer de que modo Kant leva o "Eu é um outro..." de Rimbaud mais longe.

\footnotetext{
${ }^{9}$ Rimbaud, carta a Izambart, maio de 1871, carta a Demeny, 15 de maio de 1871.
} 
Sabe-se somente que algo se compõe, suscita um deslocamento, um movimento de contração e distensão, uma desconfiança, uma emoção.

Dalcroze falava de alegrias, sístoles e diástoles. Neste sentido já estamos muito próximos de Bergson, mas principalmente de Espinosa, dos bons encontros, dos afetos que alçam uma potência a um estado de variação mais perfeito.

Algo ressoa em pontos específicos. Nem tudo ressoa em tudo. É uma questão material que impede que o mundo seja uma perfeita ressonância. Restam meados de mundos, cruzamentos de ideias afins que abrem, com alegria, um mundo a outros mundos.

Mais do que pontes, é preciso, como ensina o prof. Luiz B. L. Orlandi, produzir estreitas "banguelas" que nos conduzem humildemente a um espaço que já estamos aptos a explorar.

Neste sentido, Gramani não produz conceitos, mas seu senso invulgar do empirismo toca e repercute, como o tambor leibniziano, muitos mundos e pontos brilhantes da filosofia; um deles esbarra na concepção duvidosa da desmesura rítmica que enfrenta as evidências de uma razão aritmética.

Afeito a uma fina (e sigilosa) matemática diferencial, na qual o ritmo é sempre um "entre", Gramani nos propõe o transbordamento da estrutura pelo corpo; corpo que the dá o volume da experiência, que a infla de dentro: um volume físico e social, cultural e ético.

\section{Referências}

ALLIEZ, Éric. Deleuze Filosofia Virtual. São Paulo: Editora 34, 1996.

COELHO, Marcelo Pereira, Ritmo com acento: uma proposta de aplicação da polirritmia desenvolvida por José Eduardo Gramani no processo composicional da suíte I Juca Pirama. Campinas, 2008. 343 f. Tese (Doutorado em Música) Departamento de Música, Instituto de Artes da Universidade Estadual de Campinas.

DALCROZE, Émile Jaques. L'éducation par le rythme et pour le rythme. In: Rythme 2009. Disponível em < http://www.fier.com/wordpress/documents/le-rythmearchives/> Acessado em abril de 2011.

DELEUZE, Gilles. Crítica e Clínica. São Paulo: Editora 34, 1997. 171 p.

DELEUZE, Gilles. Diferença e Repetição. São Paulo: Graal, 2006. 437 p. 
DELEUZE, Gilles; GUATTARI, Félix. Mil Platôs: capitalismo e esquizofrenia. Volume 4. São Paulo: Editora 34, 2005. 170 p.

DELEUZE, Gilles. GUATTARI, Félix. O que é a Filosofia? São Paulo: Editora 34, 1992. 279 p.

FERRAZ, Silvio. Música e Repetição: a diferença na composição contemporânea. São Paulo: EDUC, 1998. 273 p.

GELEWSKI, Rolf. Rítmica Métrica, um método didático para o ensino de rítmica. Salvador: Edição da UFBA, 1967. 37 f.

GRAMANI, José Eduardo. Rítmica. 4a edição. São Paulo: Perspectiva, 2010. 205 p. . Rítmica. Campinas: Minaz, 1988, 120 p. Edição bilíngue. . Rítmica Viva. Campinas: Editora da UNICAMP, 1996. 214 p.

PELBART, Peter Pál. O tempo não-reconciliado. São Paulo: Perspectiva, 1998.

RODRIGUES, Indioney. O gesto pensante: A proposta de educação rítmica polimétrica de José Eduardo Gramani. São Paulo, 2001. 366 f. Dissertação (Mestrado em Artes) - Departamento de Música, Escola de Comunicação e Artes da Universidade Estadual de São Paulo.

STRAVINSKY, I; CRAFT, R. Conversas com Igor Stravinsky. São Paulo: Perspectiva, 1999. 